\title{
ASSESSMENT OF ADRENOCORTICAL RESERVE CAPACITY AND INFLAMMATORY PARAMETERS IN CRITICALLY ILL DOGS
}

\author{
Judit CSÖNDES ${ }^{1 *}$, Ibolya FÁBIÁN ${ }^{2}$, Bernadett SzABÓ ${ }^{1}$, Ákos MÁTHÉ ${ }^{3}$ \\ and Péter VAJDOVICH ${ }^{1}$ \\ ${ }^{1}$ Department of Clinical Pathology and Oncology, ${ }^{2}$ Department of Biomathematics and \\ Informatics and ${ }^{3}$ Department and Clinic of Internal Medicine, University of Veterinary \\ Medicine, István u. 2, H-1078 Budapest, Hungary
}

(Received 10 July 2017; accepted 6 November 2017)

Inflammatory markers and adrenocorticotropic hormone (ACTH) stimulation test results may help us recognise critically ill dogs with poor disease outcome. Systemic inflammatory response syndrome (SIRS) criteria, the fast version of the Acute Patient Physiologic and Laboratory Evaluation Score (APPLE $E_{\text {fast }}$ ), complete blood count, albumin and C-reactive protein (CRP) levels, baseline and stimulated cortisol levels and $\Delta$ cortisol value were recorded in 50 client-owned dogs admitted to the Small Animal Hospital of the University of Veterinary Medicine Budapest with various inflammatory or neoplastic conditions. Increasing APPLE $_{\text {fast }}$ score was associated with a decreasing chance of survival $(\mathrm{P}=0.0420)$. The $\Delta$ cortisol value was significantly higher in SIRS dogs than in non-SIRS dogs (mean \pm SD $\Delta$ cortisol $_{\text {SIRS: }} 342.5 \pm 273.96$; mean \pm SD $\Delta$ cortisol $_{\text {non-SIRs: }}: 175.3 \pm$ $150.35 ; \mathrm{P}=0.0443)$. Elevated baseline or stimulated cortisol levels were associated with a higher chance of non-survival $(P=0.0135$ and $P=0.0311$, respectively). These data indicate that pathologically higher baseline and stimulated cortisol levels represent an exaggerated stress response in critically ill dogs, which is negatively associated with survival.

$\operatorname{dog}$

Key words: SIRS, ACTH stimulation test, adrenal dysfunction, outcome,

Critical illness-related corticosteroid insufficiency (CIRCI) is a well-known entity in human medicine (Beishuizen and Thijs, 2001; Venkatesh and Cohen, 2011) and has been described in dogs (Goy-Thollot et al., 2006; Burkitt et al., 2007; Martin et al., 2008; Burkitt Creedon, 2015) as well. During critical illness, circulating cortisol contributes to maintaining vascular tone and integrity, aug-

*Corresponding author: E-mail: juditcsondes@gmail.com, Phone: 0036 (20)-217-2526

This is an open-access article distributed under the terms of the Creative Commons Attribution License, which permits unrestricted use, distribution, and reproduction in any medium for non-commercial purposes, provided the original author and source are credited. 
ments the effect of catecholamines, and plays a crucial role in the resolution of inflammation. Inadequate activation of the hypothalamic-pituitary-adrenal (HPA) axis leads to relative hypocortisolaemia and/or target cell glucocorticoid deficiency. CIRCI is a condition distinct from Addison's disease, accompanied by transient adrenocortical dysfunction (Galac et al., 2009; Prittie, 2009; Martin, 2011).

Beyond several hormonal and neurogenic signals, pro-inflammatory cytokines are known to activate the HPA axis. However, they are also able to inhibit the function of the HPA axis, interfering with corticotropin-releasing hormone $(\mathrm{CRH})$, adrenocorticotropic hormone $(\mathrm{ACTH})$ and cortisol release. The peripheral metabolism of cortisol at target tissue level could also be deranged (Galac et al., 2009; Prittie, 2009; Martin, 2011; Burkitt Creedon, 2015).

Early identification of patients with CIRCI should be a priority in clinical practice. The ACTH stimulation test (ACTHST) with a standard dose of synthetic ACTH $(5 \mu \mathrm{g} / \mathrm{kg}$ tetracosactide) is used to diagnose hypoadrenocorticism in dogs (Kemppainen et al., 2005). However, this supraphysiologic dose is not sensitive enough to detect slight alterations during CIRCI (Beishuizen and Thijs, 2001; Martin et al., 2007; Prittie, 2009; Behrend et al., 2013). It is more accurate to assess adrenocortical reserve capacity in critically ill dogs with $0.5 \mu \mathrm{g} / \mathrm{kg}$ tetracosactide (Martin et al., 2007; Martin, 2011).

Serum C-reactive protein (CRP) is the main positive acute-phase protein in dogs, produced almost exclusively by hepatocytes in response to circulating proinflammatory mediators (Gebhardt et al., 2009). The elevation of CRP reflects the severity and extension of systemic inflammation irrespective of the underlying mechanism (infection, immune-mediated disease, trauma, neoplasia, etc.), and thus CRP is used as a biomarker of systemic inflammatory response syndrome (SIRS) (de Laforcade, 2009; Gebhardt et al., 2009; Whittemore et al., 2011).

A clinical scoring system including SIRS diagnostic criteria and the fast version of the Acute Patient Physiologic and Laboratory Evaluation Score (APPLE $E_{\text {fast }}$ score) is widely used in small animal medicine, as it enables a quick and objective identification of critically ill patients (de Laforcade, 2009; Gebhardt et al., 2009; Hayes et al., 2010).

The main goal of this study was to assess the relationship between inflammatory markers used in the clinical setting and ACTHST results in critically ill dogs. In addition, we also investigated the relationship of cortisol levels and $\Delta$ cortisol value with survival.

\section{Materials and methods}

\section{Study population}

Fifty client-owned dogs with suspected SIRS admitted to the Small Animal Hospital of the University of Veterinary Medicine Budapest (UVMB) between January 2014 and August 2016 were included in the study, with various 
inflammatory or neoplastic conditions. Patients having pre-existing adrenal disease or receiving medications affecting the HPA axis (e.g. glucocorticoids, progestin, major analgesics, azole antifungals) were excluded. All dogs underwent a complete physical examination, and blood was obtained within $24 \mathrm{~h}$ after hospital admission. Patients were considered having SIRS when they fulfilled at least two out of four criteria (Table 1) (de Laforcade, 2009). The APPLE fast $_{\text {score (cal- }}$ culated from albumin, glucose and lactate level, mentation score, and platelet count) was recorded in all dogs (Hayes et al., 2010). ACTHST was performed by administering $0.5 \mu \mathrm{g} / \mathrm{kg}$ of a synthetic ACTH compound (Synachten $250 \mu \mathrm{g} / \mathrm{ml} \mathrm{inj.,}$ Novartis) intravenously. Serum cortisol level was measured prior to and $60 \mathrm{~min}$ after ACTH administration. The $\Delta$ cortisol value was calculated $[\Delta$ cortisol $=$ (stimulated cortisol) - (baseline cortisol)]. The final diagnoses were established based on medical history, clinical signs, routine laboratory and diagnostic imaging, cytology/histopathology findings and/or the pathology report. Dogs classified as survivors were alive when discharged from the Intensive Care Unit. Dogs were classified as non-survivors if they died or were euthanised during the hospitalisation period. Patients euthanised due to financial considerations were excluded. The owners of all enrolled dogs gave their written consent to the hospitalisation and treatment of their dogs.

Table 1

Criteria for the diagnosis of systemic inflammatory response syndrome (SIRS) in dogs (de Laforcade, 2009)

\begin{tabular}{ll}
\hline Criterion & Value \\
Body temperature & $<38.1{ }^{\circ} \mathrm{C}$ or $>39.2{ }^{\circ} \mathrm{C}$ \\
Heart rate & $>120 / \mathrm{min}$ \\
Respiratory rate & $>20 / \mathrm{min}$ \\
White blood cell count, band neutrophil ratio & $<6.0 \mathrm{G} / 1$ or $>16.0 \mathrm{G} / 1,>3 \%$
\end{tabular}

Sample collection, handling and analysis

Venous blood was obtained and samples for haematology and clinical chemistry were immediately analysed or stored overnight at $4{ }^{\circ} \mathrm{C}$. Serum samples for CRP and cortisol assay were stored at $-20^{\circ} \mathrm{C}$ until assayed. Complete blood count was done with Abacus Junior Vet 5 Analyzer (Diatron) and each blood film was evaluated microscopically. The biochemistry panel was performed using an Olympus AU400 Chemistry Analyser. Serum C-reactive protein levels were determined from 33 patients by an immunoturbidimetric method previously validated for canine samples (Canine CRP Diasystem Scandinavia) according to the manufacturer's instruction. Serum cortisol concentrations were determined using a chemiluminescent immunoassay (Immulite1000, Siemens) validated for use with canine serum samples. Concentrations above the detection range (corti- 
sol $>1380 \mathrm{nmol} / 1$; CRP $>220 \mathrm{mg} / \mathrm{l}$ ) were reported as cortisol $1380 \mathrm{nmol} / 1$ and CRP $220 \mathrm{mg} / \mathrm{l}$. None of the samples were extremely haemolytic or lipaemic.

\section{Statistical analysis}

Statistical analysis was done by the statistical program R 3.2.3 (R Core Team, 2015). Variables of interest were baseline and stimulated cortisol level, $\Delta$ cortisol value, body temperature, SIRS criteria, APPLE $E_{\text {fast }}$ score, total white blood cell (WBC) count, absolute number of band neutrophils and lymphocytes, albumin level and C-reactive protein concentration.

For the continuous variables ( $\Delta$ cortisol value, body temperature, $\mathrm{APPLE}_{\text {fast }}$ score, total WBC count, absolute number of band neutrophils and lymphocytes, albumin level and C-reactive protein concentration) mean \pm SD and ranges are reported, and group comparisons were made by Student's $t$-test and Spearman's rank correlation. For the comparison of categorical variables (SIRS criteria, survival criteria, baseline and stimulated cortisol level) Fisher's exact test was done. A logistic regression model was used to assess the strength of the relationship between APPLE $_{\text {fast }}$ score and disease outcome. ACTHST was performed in all dogs, but the stimulated cortisol level of two dogs was not measured due to insufficient sample volume, and four patients with cortisol levels $\mathrm{t}_{0}$ and/or $\mathrm{t}_{\mathrm{hh}}>1380 \mathrm{nmol} / \mathrm{l}$ were excluded from the statistical analysis. The cut-off value of $\Delta$ cortisol was calculated from data of 44 dogs to predict the chance of survival. For the statistical analyses dogs were pooled in the following groups: baseline cortisol levels within the reference interval $(40-110 \mathrm{nmol} / \mathrm{l})$ or elevated $(\geq 110 \mathrm{nmol} / \mathrm{l})$, stimulated cortisol levels within $(150-470 \mathrm{nmol} / \mathrm{l})$, above $(>470 \mathrm{nmol} / \mathrm{l})$ or below $(<150 \mathrm{nmol} / \mathrm{l})$ the reference range. A value of $\mathrm{P}<0.05$ was considered significant for all tests.

\section{Results}

The 50 dogs meeting the inclusion criteria included 26 males (12 castrated) and 24 females (13 spayed). The breeds represented included 7 mixed-breed dogs, 4 German Shepherds, 3 Yorkshire Terriers and Golden Retrievers each, 2 Bichon Bolognese, Bichon Havanese, English Cocker Spaniels, Dachshund, Dobermans, Pugs, West Highland White Terriers each, and one dog each of 19 other breeds. The median age was 7 years (range: 5 months to 15.5 years). The mean age of nonsurvivors ( $8.7 \pm 3.8$ years, range: $0.9-15.5$ years $)$ was significantly higher than that of the survivors $(6.4 \pm 3.7$ years, range: $0.4-13.5$ years, $\mathrm{P}=0.0461)$. The median body weight was $22.5 \mathrm{~kg}$ (range: $2-65 \mathrm{~kg}$ ). Forty-one dogs $(82 \%)$ were diagnosed with inflammatory disease: peritonitis $(n=8)$, inflammatory bowel disease $(n=5)$, acute haemorrhagic diarrhoea syndrome $(n=3)$, septicaemia $(n=3)$, fever of unknown origin $(n=2)$, diabetes mellitus and pancreatitis $(n=2)$, pleuropneumonia $(n=2)$, bronchopneumonia $(n=2)$, aspiration pneumonia $(n=2)$, septic pleuritis 
$(n=2)$, bite wounds $(n=2)$, immune-mediated haemolytic anaemia $(n=2)$, gastroenteritis $(n=1)$, endocarditis $(n=1)$, mastitis $(n=1)$, abscess $(n=1)$, babesiosis $(\mathrm{n}=1)$, immune-mediated polyarthritis $(\mathrm{n}=1)$. Nine dogs $(18 \%)$ had neoplastic disorders: mammary gland carcinoma $(\mathrm{n}=2)$, small-cell lung carcinoma $(\mathrm{n}=1)$, high-grade multicentric lymphoma $(\mathrm{n}=1)$, alimentary B-cell lymphoma $(\mathrm{n}=1)$, high-grade squamous cell carcinoma $(\mathrm{n}=1)$, metastatic haemangiosarcoma $(\mathrm{n}=$ $1)$, pulmonary metastasis $(\mathrm{n}=1)$, and abdominal sarcoma $(\mathrm{n}=1)$.

The majority of the dogs $(32 / 50 ; 64 \%)$ were discharged from the hospital, but $18 / 50$ patients $(36 \%)$ died or were euthanised during the hospitalisation period.

Overall, 32/50 dogs (64\%) fulfilled the diagnostic criteria for SIRS: 5/9 patients $(56 \%)$ with neoplasia and $27 / 41$ dogs $(66 \%)$ with inflammatory disease. Disease outcome did not differ in the SIRS and non-SIRS groups. There was no correlation between SIRS and baseline or stimulated cortisol concentration, but the $\Delta$ cortisol value was significantly different in the SIRS and non-SIRS groups (mean $\Delta$ cortisol $_{\text {SIRS: }} 342.5 \pm 273.96 \mathrm{nmol} / 1$ and mean $\Delta$ cortisol $_{\text {non-SIRS: }} 175.3 \pm$ $150.35 \mathrm{nmol} / 1, \mathrm{P}=0.0148$ ) (Fig. 1).

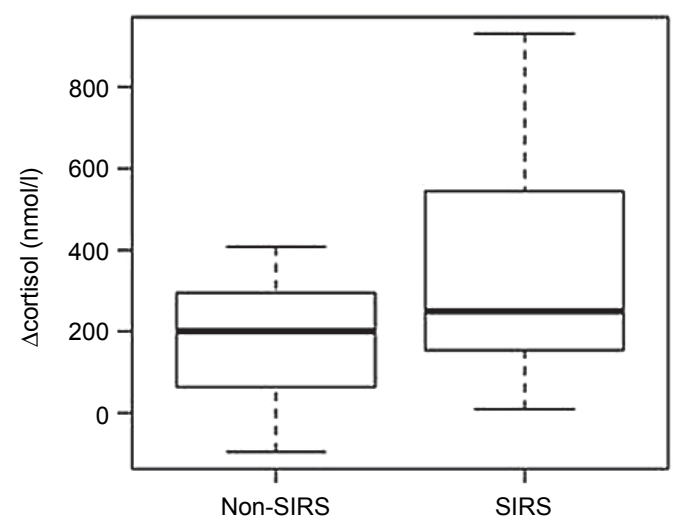

Fig. 1. $\Delta$ cortisol value of the SIRS and the non-SIRS group (mean $\Delta$ cortisol $_{\text {SIRS }}: 342.5 \pm$ $273.96 \mathrm{nmol} / \mathrm{l}$, mean $\Delta$ cortisol $\left._{\text {non-SIRs }}: 175.3 \pm 150.35 \mathrm{nmol} / \mathrm{l} ; \mathrm{P}=0.0148\right)$

There was no significant correlation between APPLE $_{\text {fast }}$ score and cortisol $\mathrm{t}_{0}, \mathrm{t}_{1 \mathrm{~h}}$ levels or $\Delta$ cortisol value. However, there was a significant relationship between increasing APPLE ${ }_{\text {fast }}$ score and decreasing chance of survival [mean for survivors: $24.09 \pm 3.62$, mean for non-survivors $26.89 \pm 5.29$, OR $=0.86$, CI $95 \%$ : (0.79; 0.92), $\mathrm{P}=0.042$ ] (Fig. 2).

The rectal temperature was recorded at the time of blood sampling. Thirtyone patients $(62 \%)$ had normal body temperature $\left(38.0-39.2{ }^{\circ} \mathrm{C}\right), 8$ dogs $(16 \%)$ had fever, and 11 dogs (22\%) were suffering from hypothermia. Higher body temperature was statistically correlated with elevated serum CRP concentration (Spearman's rank correlation, $\mathrm{P}=0.0255, \rho=0.39$ ). 


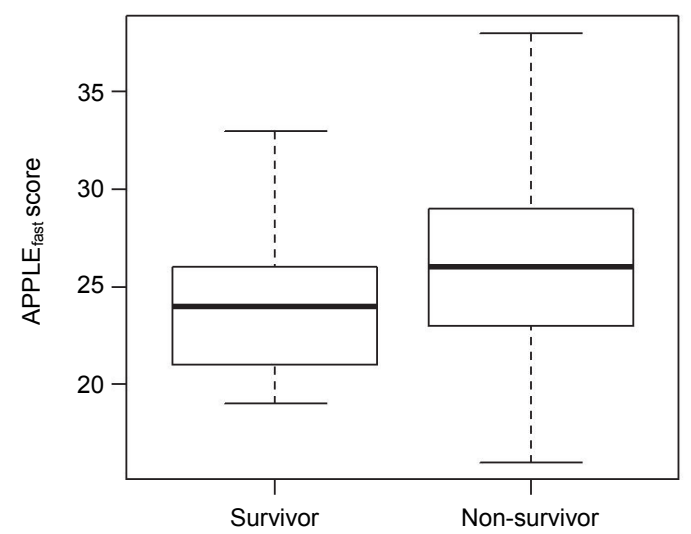

Fig. 2. APPLE $E_{\text {fast }}$ score in survivor and non-survivor dogs $\left[\operatorname{mean}_{\text {survivor }}: 24.09 \pm 3.62\right.$, mean $_{\text {non-survivor }}: 26.89 \pm 5.29 ; \mathrm{OR}=0.86, \mathrm{CI} 95 \%$ : $\left.(0.79 ; 0.92), \mathrm{P}=0.042\right]$

Serum C-reactive protein was measured in 33 patients, all of which had elevated values $\left(\right.$ median $_{\text {crp: }}: 101.6 \mathrm{mg} / \mathrm{dl}$, mean ${ }_{\text {crp }}: 130.6 \pm 87.20 \mathrm{mg} / \mathrm{dl}$, range: $18.9-406.1 \mathrm{mg} / \mathrm{dl}$ ). Although the mean CRP concentrations of non-survivors were higher than those of survivors, the difference was not significant (Table 2). Similarly, the mean CRP level showed no significant difference between the SIRS group $(146.4 \pm 94.5 \mathrm{mg} / \mathrm{dl})$ and the non-SIRS group $(109.1 \pm 74.0 \mathrm{mg} / \mathrm{dl})$. CRP was not significantly correlated with cortisol $\mathrm{t}_{0}$ or $\mathrm{t}_{\mathrm{lh}}$ concentrations.

The WBC, band neutrophil and lymphocyte counts and albumin concentration were not correlated significantly with the outcome. In addition, there was no difference in albumin level between survivor and non-survivor individuals (Table 2).

Elevated baseline cortisol level was associated with an almost ten times higher chance of non-survival compared to dogs with baseline cortisol within the reference range $(\mathrm{OR}=9.71, \mathrm{P}=0.0135)$ (Fig. 3).

Patients with stimulated cortisol levels above the reference range had an almost four times higher chance of non-survival compared to dogs with cortisolt $_{1 \mathrm{~h}}$ within or below the reference interval $(\mathrm{OR}=3.69, \mathrm{P}=0.0311)$ (Fig. 4).

Four patients had baseline and/or stimulated cortisol levels higher than $1380 \mathrm{nmol} / \mathrm{l}$. Three of them were non-survivors (pancreatitis with peritonitis, mammary tumour, peritonitis due to foreign body ileus), and only one dog (with babesiosis and implant-related infection in the tibia) was discharged from the hospital.

The $\Delta$ cortisol value was not significantly different in survivor and nonsurvivor patients (Table 2). However, the $\Delta$ cortisol value was significantly higher in SIRS dogs than in non-SIRS dogs (mean $\Delta$ cortisol $_{\text {SIRS: }} 342.5 \pm 273.96$; mean $\Delta$ cortisol $\left._{\text {non-SIRS: }} 175.3 \pm 150.35 ; \mathrm{P}=0.0443\right)$. There was no $\Delta$ cortisol cut-off value of acceptable sensitivity and specificity suitable for clinical decision-making. 


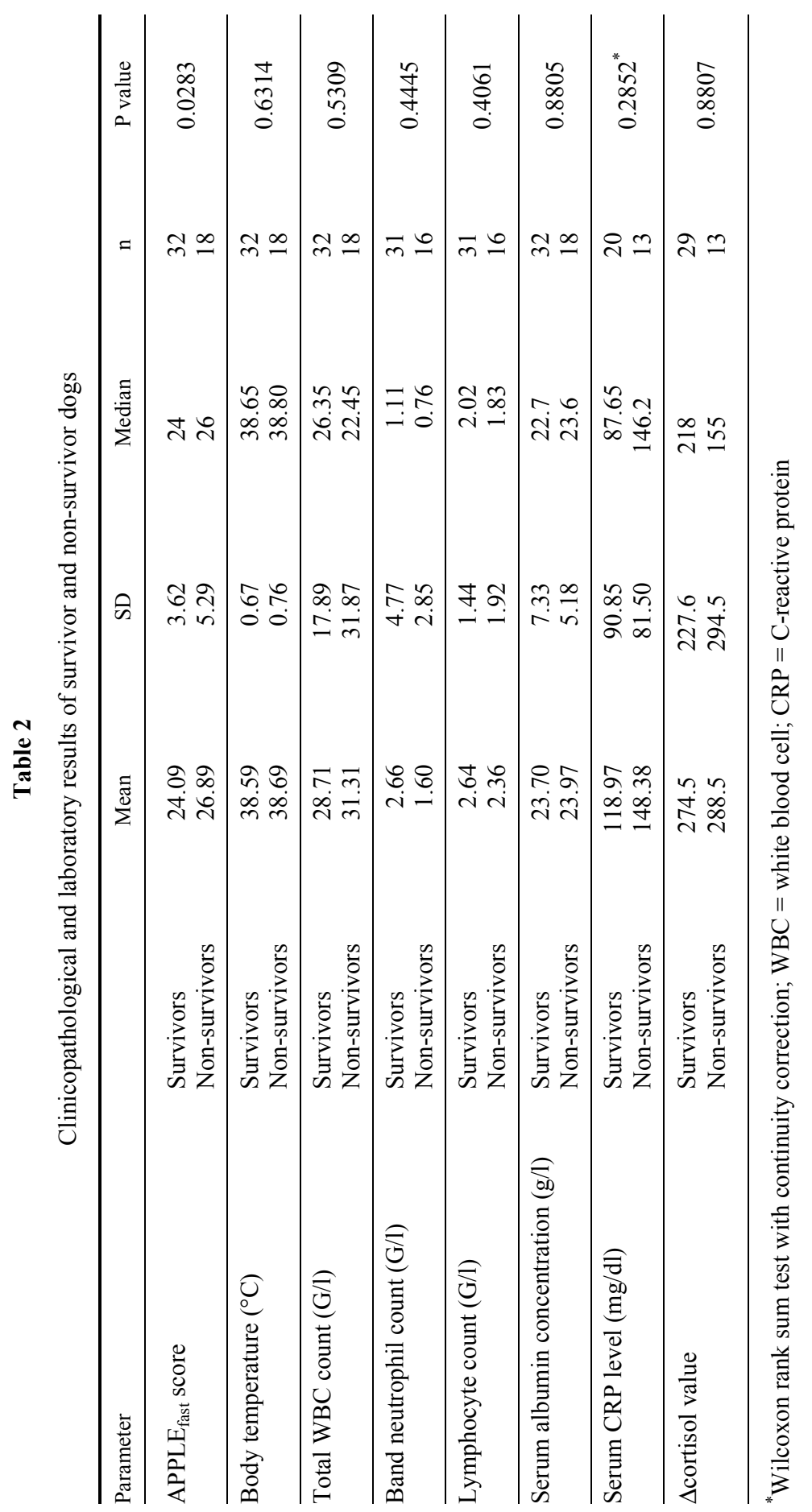




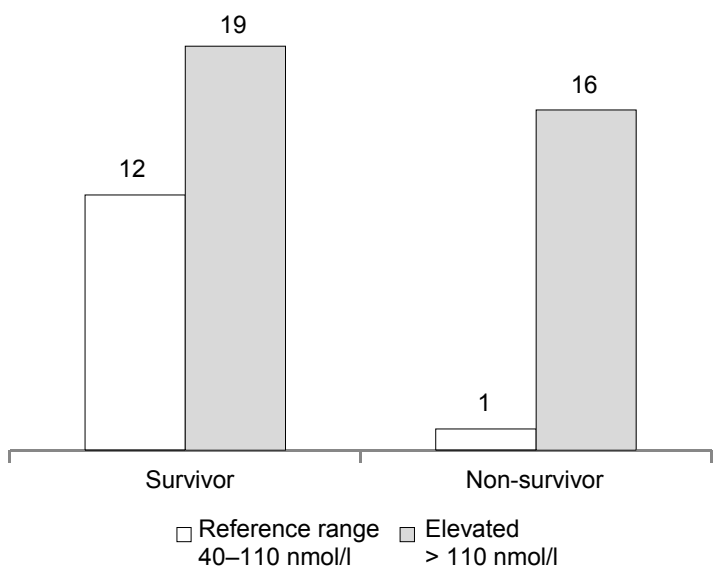

Fig. 3. Baseline cortisol level in survivor and non-survivor dogs $(\mathrm{OR}=9.71, \mathrm{P}=0.0135)$

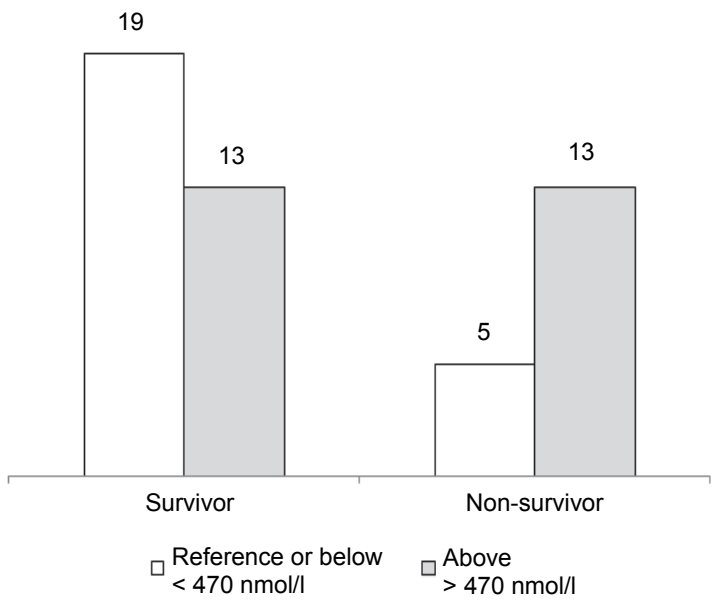

Fig. 4. Stimulated cortisol level in survivor and non-survivor dogs $(\mathrm{OR}=3.69, \mathrm{P}=0.0311)$

\section{Discussion}

The main purpose of our study was to assess adrenocortical reserve capacity in critically ill dogs and evaluate the possible relationship between the severity of inflammation and adrenal responsiveness.

In conformity with the results reported by Giunti et al. (2015), the mortality rate found in the present study was high and the use of the APPLE $\mathrm{F}_{\text {fast }}$ score was helpful in predicting poor disease outcome at the time of hospital admission.

Our data indicate that a single serum CRP determined at the time of hospital admission has limited diagnostic value as a marker of survival. Similar find- 
ings were reported by Whittemore et al. (2011) and Giunti et al. (2015). In another study of $61 \mathrm{dogs}$ with septic or non-septic SIRS, the initial serum CRP concentration was not associated with disease outcome, but the changes observed in a 3-day period had a predictive value regarding survival (Gebhardt et al., 2009). Changes in CRP levels in response to therapy could have been more accurate in predicting survival in our study population as well. Not surprisingly, body temperature was correlated with C-reactive protein level, as both are consequences of the acute-phase response generated by pro-inflammatory mediators.

Although in our study there was no relationship between CRP and ACTHST cortisol concentrations, we find it useful to report even this negative finding, as to the best of our knowledge this correlation had not been studied previously.

We found that the $\Delta$ cortisol value was significantly higher in the SIRS than in the non-SIRS group. This is a correlation that has never been reported before as far as we know. However, this finding is slightly controversial. On the one hand, patients not suffering from SIRS are not sick enough to have an exaggerated adrenal response, but on the other hand some dogs with SIRS are expected to have a blunted cortisol response to ACTH. A possible explanation could be that corticosteroid insufficiency is manifested at the receptor level in target cells in patients with SIRS, and even an exaggerated cortisol response to ACTH is not sufficient to meet the cellular demand (Beishuizen and Thijs, 2001; Venkatesh and Cohen, 2011; Burkitt Creedon, 2015). Cellular glucocorticoid deficiency should be investigated in these cases.

Regarding C-reactive protein level, there was no statistically significant difference between the SIRS group and the non-SIRS group. A possible explanation could be that the patients were misclassified regarding their SIRS status: according to de Laforcade (2009), diagnostic criteria for SIRS in dogs have a specificity of only $64 \%$ and a sensitivity of $97 \%$.

Like in previous studies, none of our patients had absolute baseline hypocortisolaemia or abnormal $\mathrm{Na}^{+} / \mathrm{K}^{+}$ratio according to the reference interval established for healthy dogs (Prittie et al., 2002; Goy-Thollot et al., 2006; Martin et al., 2008). Nevertheless, there is no widely accepted reference range for plasma cortisol level in critically ill dogs (Prittie, 2009; Martin, 2011). Sweeney et al. (2010) investigated cortisol levels in response to ACTHST in healthy dogs that underwent different intensive care procedures (sedation, tracheostomy, intubation and mechanical ventilation, etc.), but these dogs were not sick, so the effect of inflammation on the HPA axis could not be extrapolated.

Our findings are consistent with the results of previous studies in demonstrating a positive association between elevated baseline or post-ACTH cortisol level and a decreased chance of survival (Goy-Thollot et al., 2006; Schoeman et al., 2007; Schoeman and Herrtage, 2008).

Blunted response to the ACTH stimulation test is identified as an independent predictor of poor prognosis in human septic patients (Juutilainen et al., 
2011). Moreover, the relationship between inappropriate adrenocortical reserve capacity and increased risk of death in dogs has been reported: Burkitt et al. (2007) found that a $\Delta$ cortisol value of $<83 \mathrm{nmol} / 1$ was associated with increased risk of hypotension and poor prognosis in septic dogs. However, the intramuscularly administered synthetic ACTH injection $(250 \mu \mathrm{g} /$ patient $)$ might not be properly absorbed in a hypotensive patient. In another study, dogs with sepsis, trauma or gastric dilatation and overload were investigated: patients having a $\Delta$ cortisol value of $\leq 83 \mathrm{nmol} / 1$ (after $5 \mu \mathrm{g} / \mathrm{kg}$ ACTH iv.) were 5.7 times more likely to be treated with vasopressors compared to dogs with $\Delta$ cortisol $>83 \mathrm{nmol} / \mathrm{l}$, but the difference regarding disease outcome was not significant (Martin et al., 2008). Schoeman and Herrtage (2008) examined adrenal responsiveness to $5 \mu \mathrm{g} / \mathrm{kg}$ ACTH in dogs with Babesia rossi infection. Non-survivor dogs tended to have lower $\Delta$ cortisol values compared to survivors, but the difference was not statistically significant. In contrast, Goy-Thollot et al. (2006) found that $\Delta$ cortisol values were higher in non-survivors than in survivors after intravenous injection of $250 \mu \mathrm{g}$ ACTH to critically ill dogs.

In our study we did not find statistically significant differences in $\Delta$ cortisol value between survivor and non-survivor dogs. Nevertheless, 17 of the 18 non-survivor individuals had elevated baseline and/or stimulated cortisol level. These dogs might have suffered from CIRCI at the receptor level (target cell hypocortisolism), because they died in face of their hypercortisolaemia. Detailed investigation of changes in glucocorticoid receptor profiles of target cells is also recommended and may be helpful in understanding the pathomechanism of CIRCI.

The influence of the patients' age on disease outcome should be considered in critically ill dogs, as in the present study survivors were significantly younger than non-survivors.

The inclusion of patients with neoplasia might distort the statistical calculations regarding disease outcome, but SIRS and CIRCI can also develop due to an underlying neoplastic condition (Boozer et al., 2005; Bruno et al., 2012).

As with any clinical study, there are several limitations that should be considered. The study population was heterogeneous in terms of their illness; however, SIRS could develop irrespective of the underlying condition (de Laforcade, 2009). The accurate onset of critical illness in the patients studied was also unknown. Furthermore, patients prior to hospitalisation could have been already treated with intravenous fluids, antibiotics, NSAIDs, etc., which could influence the test results and the disease outcome. However, patients receiving medications that could directly alter the HPA axis (i.e. glucocorticoids) were excluded from the study.

The small size of study population could also limit the extension of our results. In addition, our findings might be relevant in the Small Animal Hospital of the UVMB and might not be applicable to other institutes. 
Measurement of the free fraction of cortisol rather than total cortisol level has been suggested in critically ill patients, especially in those with hypoalbuminaemia (Goy-Thollot et al., 2006; Martin, 2011; Venkatesh and Cohen, 2011). Like albumin level, the serum concentration of cortisol-binding globulin (CBG), which is the main carrier molecule of circulating cortisol, wanes during inflammation. Decrease in CBG level leads to an elevated unbound, free cortisol concentration. The measurement of total cortisol level might underestimate the circulating free cortisol level. Although the determination of free cortisol level would have been more accurate for evaluating the degree of hypercortisolaemia in our patients, unfortunately it was not available to us. However, it probably would not change our conclusions, as there was no difference in albumin level between survivor and non-survivor individuals.

Further studies are necessary to clarify the relationship between systemic inflammation and adrenocortical reserve capacity. Serial measurement of plasma pro-inflammatory cytokines and/or acute-phase proteins could provide a more accurate follow-up of ongoing inflammatory process, and repeated ACTHST would be more ideal for assessing adrenocortical reserve capacity during critical illness.

\section{Acknowledgements}

We wish to express our thanks to Ildikó Leiner for her dedicated laboratory assistance. The publication of this research was supported by the 12190-4/2017/ FEKUTSTRAT grant of the Hungarian Ministry of Human Capacities.

\section{References}

Behrend, E. N., Kooistra, H. S., Nelson, R., Reusch, C. E. and Scott-Moncrieff, J. C. (2013): Diagnosis of spontaneous canine hyperadrenocorticism: 2012 ACVIM Consensus Statement (Small Animal). JVIM 27, 1292-1304.

Beishuizen, A. and Thijs, L. G. (2001): Relative adrenal failure in intensive care: an identifiable problem requiring treatment? Best Pract. Res. Clin. Endocrinol. Metab. 15, 513-531.

Boozer, A. L., Behrend, E. N., Kemppainen, R. J., Whitley, E. M., Smith, A. N. and Busch, K. A. (2005): Pituitary-adrenal axis function in dogs with neoplasia. Vet. Comp. Oncol. 3, 194-202.

Bruno, J. J., Hernandez, M., Ghosh, S. and Pravinkumar, S. E. (2012): Critical illness-related corticosteroid insufficiency in cancer patients. Support. Care Cancer 20, 1159-1167.

Burkitt, J. M., Haskins, S. C., Nelson, R. W. and Kass, P. H. (2007): Relative adrenal insufficiency in dogs with sepsis. JVIM 21, 226-231.

Burkitt Creedon, J. M. (2015): Controversies surrounding critical illness-related corticosteroid insufficiency in animals. J. Vet. Emerg. Crit. Care 25, 107-112.

de Laforcade, A. M. (2009): Systemic inflammatory response syndrome. In: Silverstein, D. C. and Hopper, K. (eds) Small Animal Emergency and Critical Care Medicine. Saunders Elsevier, St. Louis, MO. pp. 46-49. 
Galac, S., Reusch, C. E., Kooistra, H. S. and Rijnberk, A. (2009): Relative adrenocortical insufficiency. In: Rijnberk, A. and Kooistra, H. S. (eds) Clinical Endocrinology of Dogs and Cats. Schlütersche, Hannover. pp. 110-111.

Gebhardt, C., Hirschberger, J., Rau, S., Arndt, G., Krainer, K., Schweigert, F. J., Brunnberg, L., Kaspers, B. and Kohn, B. (2009): Use of C-reactive protein to predict outcome in dogs with systemic inflammatory response syndrome or sepsis. J. Vet. Emerg. Crit. Care 19, $450-458$.

Giunti, M., Troia, R., Bergamini, P. F. and Dondi, F. (2015): Prospective evaluation of the acute patient physiologic and laboratory evaluation score and an extended clinicopathological profile in dogs with systemic inflammatory response syndrome. J. Vet. Emerg. Crit. Care 25, 226-233.

Goy-Thollot, I., Decosne-Junot, C. and Bonnet, J-M. (2006): Adrenal responsiveness in critically ill dogs: prospective study. Rev. Méd. Vét. 157, 213-218.

Hayes, G., Mathews, K., Doig, G., Boston, S., Nykamp, S., Poljak, Z. and Dewey, C. (2010): The Acute Patient Physiologic and Laboratory Evaluation (APPLE) score: A severity of illness stratification system for hospitalized dogs. JVIM 24, 1034-1047.

Juutilainen, A., Hämäläinen, S., Niemenpää, J., Kuittinen, T., Pulkki, K., Koivula, I., Niskanen, L. and Jantunen, E. (2011): Serum cortisol and inflammatory response in neutropenic fever. Ann. Hematol. 90, 1467-1475.

Kemppainen, R. J., Behrend, E. N. and Busch, K. A. (2005): Use of compounded adrenocorticotropic hormone (ACTH) for adrenal function testing in dogs. JAAHA 41, 368-372.

Martin, L. G. (2011): Critical illness-related corticosteroid insufficiency in small animals. Vet. Clin. Small Anim. 41, 767-782.

Martin, L. G., Behrend, E. N., Mealey, K. L., Carpenter, D. M. and Hickey, K. C. (2007): Effect of low doses of cosyntropin on serum cortisol concentrations in clinically normal dogs. Am. J. Vet. Res. 68, 555-560.

Martin, L. G., Groman, R. P., Fletcher, D. J., Behrend, E. N., Kemppainen, R. J., Moser, V. R. and Hickey, K. C. (2008): Pituitary-adrenal function in dogs with acute critical illness. JAVMA 233, 87-95.

Prittie, J. E. (2009): Adrenal insufficiency in critical illness. In: Bonagura, J. D. and Twedt, D. C. (eds) Kirk's Current Veterinary Therapy XIV. Elsevier, Philadelphia. pp. 228-230.

Prittie, J. E., Barton, L. J., Peterson, M. E., Kemppainen, R. J., Herr, L. G. and Fox, P. R. (2002): Pituitary ACTH and adrenocortical secretion in critically ill dogs. JAVMA 220, 615-619.

Schoeman, J. P. and Herrtage, M. E. (2008): Adrenal response to the low dose ACTH stimulation test and the cortisol-to-adrenocorticotrophic hormone ratio in canine babesiosis. Vet. Parasitol. 154, 205-213.

Schoeman, J. P., Rees, P. and Herrtage, M. E. (2007): Endocrine predictors of mortality in canine babesiosis caused by Babesia canis rossi. Vet. Parasitol. 148, 75-82.

Sweeney, D. A., Natanson, Ch., Banks, S. M., Solomon, S. B. and Behrend, E. N. (2010): Defining normal adrenal function testing in the intensive care unit setting: A canine study. Crit. Care. Med. 38, 553-561.

Venkatesh, B. and Cohen, J. (2011): Adrenocortical (dys)function is septic shock - A sick euadrenal state. Best Pract. Res. Clin. Endocrinol. Metab. 25, 719-733.

Whittemore, J. C., Marcum, B. A., Mawby, D. I., Coleman, M. V., Hacket, T. B. and Lappin, M. R. (2011): Associations among albuminuria, C-reactive protein concentrations, survival predictor index scores and survival in 78 critically ill dogs. JVIM 25, 818-824. 